\title{
Robot-assisted practice of gait and stair climbing in nonambulatory stroke patients
}

\author{
Stefan Hesse, MD; ${ }^{*}$ Christopher Tomelleri, PhD; ${ }^{2}$ Anita Bardeleben, MA; ${ }^{1}$ Cordula Werner, MA; ${ }^{1}$ Andreas \\ Waldner, $\mathbf{M D}^{2}$ \\ ${ }^{1}$ Department of Neurological Rehabilitation, Medical Park Berlin, Charité-Universitätsmedizin Berlin, Berlin, Germany; \\ ${ }^{2}$ Department of Neurological Rehabilitation, Villa Melitta, Bolzano, Italy
}

\begin{abstract}
A novel gait robot enabled nonambulatory patients the repetitive practice of gait and stair climbing. Thirty nonambulatory patients with subacute stroke were allocated to two groups. During $60 \mathrm{~min}$ sessions every workday for 4 weeks, the experimental group received $30 \mathrm{~min}$ of robot training and $30 \mathrm{~min}$ of physiotherapy and the control group received 60 min of physiotherapy. The primary variable was gait and stair climbing ability (Functional Ambulation Categories [FAC] score 0-5); secondary variables were gait velocity, Rivermead Mobility Index (RMI), and leg strength and tone blindly assessed at onset, intervention end, and follow-up. Both groups were comparable at onset and functionally improved over time. The improvements were significantly larger in the experimental group with respect to the FAC, RMI, velocity, and leg strength during the intervention. The FAC gains (mean $+/$ - standard deviation) were $2.4+/-$ 1.2 (experimental group) and $1.2+/-1.5$ (control group), $p=$ 0.01 . At the end of the intervention, seven experimental group patients and one control group patient had reached an FAC score of 5 , indicating an ability to climb up and down one flight of stairs. At follow-up, this superior gait ability persisted. In conclusion, the therapy on the novel gait robot resulted in a superior gait and stair climbing ability in nonambulatory patients with subacute stroke; a higher training intensity was the most likely explanation. A large randomized controlled trial should follow.
\end{abstract}

Clinical Trial Registration: ClinicalTrials.gov; NCT001290611, "Robot-assisted Gait and Stair Practise"; http://www.clinicaltrials.gov.

Key words: gait, hemiparesis, locomotor training, mobility, physiotherapy, rehabilitation, robots, spasticity, stair climbing, stroke.

\section{INTRODUCTION}

Stroke annually affects approximately 180 per 100,000 inhabitants in the industrialized world; it is the most common cause of persisting disabilities [1]. Restoration and improvement of independent gait are major goals of stroke rehabilitation and pivotal for aspired social and vocational integration.

Currently, a task-specific repetitive approach, i.e., numerous practices of complex gait cycles, is regarded as the most promising to restore motor function after stroke [2]. Conventional therapy, including treadmill training with partial body-weight support (BWS) [3-4], is limited by the effort to assist the patients' gait, e.g., when placing the paretic limb. Gait machines intended to relieve therapeutic effort to assist the patients' gait in combination with physiotherapy (PT) affected superior gait ability in most stroke trials [5-8] and a meta-analysis [9]. The machines, offering practice up to 1,000 steps per session, either used an exoskeleton [10-11] or an end-effector approach [12-13].

Abbreviations: BWS = body-weight support, FAC $=$ Functional Ambulation Categories, MI $=$ Motricity Index, PT = physiotherapy, RMI = Rivermead Mobility Index.

*Address all correspondence to Stefan Hesse, MD; Medical Park Berlin, Charité-Universitätsmedizin Berlin, An der Mühle 2-9, 13507 Berlin, Germany; +49-(0)30-300-240- 9271; fax: +49-(0)30-300-240-9319.

Email: s.hesse@medicalpark.de

http://dx.doi.org/10.1682/JRRD.2011.08.0142 
Most gait machines restrict themselves to the repetitive practice of simulated walking on the floor. Stair climbing up and down, however, is an integral part of everyday mobility both at home and in the community. A quarter of Berlin's subway stations offer neither an elevator nor a conveyor [14]. A large Italian cohort study included 437 nonambulatory patients with stroke; only 5 percent of them regained independent stair climbing following conventional inpatient rehabilitation [15].

The therapeutic effort needed for relearning stair climbing after stroke is considerable, especially considering the risk of falls. To ease therapist effort, a gait robot (G-EO System [Reha Technology AG; Olten, Switzerland; eo comes from Latin for "I walk") based on the end-effector principle was designed [16]. The trajectories of the foot plates and the vertical and horizontal movements of the center of mass were fully programmable, enabling wheelchair-bound subjects not only the repetitive practice of simulated floor walking but also up and down stair climbing. The lower-limb muscle activation patterns of ambulatory subjects with stroke, recorded during the real and simulated stair-climbing condition, corresponded with each other [16]. The device follows the HapticWalker, a research prototype with limited clinical applicability because of its dimensions and required high voltage, by applying the same principles of an endeffector device with programmable footplates [17-18].

This article presents the first clinical results in nonambulatory patients with subacute stroke allocated to two groups. The patients were either treated on the G-EO System in combination with PT (experimental group) or received individual PT (control group) for 4 weeks. The absolute session durations were comparable, and the PT of both groups concentrated on restoring gait, including stair climbing. We treated the two groups consecutively because of the limited availability of the G-EO System. Our hypothesis was superior gait and stair-climbing ability in the experimental group at the end of the intervention phase. The data should help to appraise the feasibility and clinical potential of the G-EO System.

\section{METHODS}

\section{Patients}

Participants comprised 30 patients with stroke from one center offering comprehensive inpatient stroke rehabilitation. The inclusion criteria were-

- Age $<80$ years old.
- First-time supratentorial stroke with stroke interval of $<10$ weeks before study onset.

- Wheelchair-mobilized and partially independent in basic activities of living (Barthel Index score from 30-55 out of 100) [19].

- Able to sit at edge of bed with hands holding on and feet placed on floor and able to stand for short period with hands holding on.

- Requiring continuous or intermittent help carrying weight and with balance during gait (Functional Ambulation Categories [FAC] score of 1 or 2 out of 5) [20].

- No severe lower-limb spasticity. Joints must reach neutral position in standing frame.

- No severe heart disease limiting participation according to examination by cardiologist that included a 12lead electrocardiogram.

- No other neurological or orthopedic disease impairing repetitive gait practice.

- No severe cognitive or communicative impairment. The first 15 patients formed the experimental group and the second 15 patients formed the control group; i.e., the two groups were treated consecutively.

\section{Intervention}

The experimental group patients had 60 min sessions of individual PT every workday for 4 weeks, i.e., 20 sessions. Within the first $30 \mathrm{~min}$, they practiced on the G-EO System. This time included donning and doffing and breaks; the intended net therapy time on the G-EO System ranged from 15 to $20 \mathrm{~min}$. One therapist, who has 10 years of experience in machine-supported gait rehabilitation, assisted the patients with putting on the harness while sitting in their wheelchair, getting onto the G-EO System in the wheelchair using a ramp from the rear, fixing the feet on the plates, hoisting the patient, attaching the lateral ropes, and setting the therapy parameters memorized by the G-EO System computer. During each session, the patients practiced 5 to 15 min of simulated floor walking followed by 5 to $10 \mathrm{~min}$ of repetitive simulated stair climbing up and down. The patient practiced a minimum of 300 steps on the simulated floor and climbed a minimum of 50 steps on the simulated stair during each session. Breaks were optional, but uninterrupted training intervals of at least $5 \mathrm{~min}$ for simulated floor walking and $3 \mathrm{~min}$ of simulated stair climbing were required. Heart rate and blood pressure were monitored at the beginning and end of each session. During the training, the therapist manually assisted knee extension while standing in front 
of the patient if needed. The treatment parameters were noted for each session, and the steps taken during simulated walking were converted into the distance covered based on chosen step length.

Another physiotherapist with 8 years of experience in stroke rehabilitation was responsible for the second $30 \mathrm{~min}$ of the session. She worked with the patients on improving gait and stair climbing in real-life situations depending on the individual impairment level. She applied a task-specific repetitive approach in conjunction with tone-inhibiting maneuvers to practice the motor tasks repetitively. Technical aids such as walking canes or orthoses could be used. The meters covered during walking and the numbers of steps climbed were noted.

The control group received 60 min of PT every workday for 4 weeks, i.e., 20 sessions, with the same physiotherapist as the experimental group. Again, she strongly emphasized the restoration and improvement of gait and stair climbing by applying a task-specific repetitive approach in conjunction with tone-inhibiting maneuvers (technical aids could be used). An assistant could help with stair climbing. The meters covered during walking and the numbers of steps climbed were also noted.

All patients participated in a comprehensive rehabilitation program. In addition to the individual PT sessions, patients performed ergometer training on a daily basis, physical therapy (30 min sessions three times a week, including massage and spa therapy), and occupational therapy (45 min sessions five times a week). The comprehensive program is intended to improve the abilities in the basic activities of daily living (sessions in the early morning to relearn washing and dressing alternating with sessions during the day to promote upper-limb recovery). Speech and neuropsychology therapies were administered on an individual basis. On Saturdays, every patient received two 30 min sessions, either PT or occupational therapy and physical therapy.

\section{Assessment}

The primary variable was the FAC, where $0=$ could not walk at all and $5=$ could walk independently anywhere, including climbing up and down one flight of stairs (8 steps) irrespective of whether in an alternate or nonalternate pattern (technical aids and a bilateral handrail could be used) [20].

Secondary variables were the Rivermead Mobility Index (RMI) of 0 to 15, which includes 15 hierarchical items from turning over in bed to running that the patient could perform (score 1 point) or not (score 0 points) [21]; the $10 \mathrm{~m}$ test to assess the mean velocity (meters per second), where the patient walked $14 \mathrm{~m}$ twice at a self-selected speed and the time on $10 \mathrm{~m}$ was taken (an experienced therapist assisted the patient, if needed, and any applied technical aids were kept constant); the lower-limb Motricity Index (MI) of 1 to 100, which tested the muscle strength of ankle dorsiflexion, knee extension, and hip flexion [22]; and lower-limb muscle tone, in which five passive movements (ankle dorsiflexion, ankle eversion, knee flexion and extension, and hip flexion) were tested while the patient laid supine using the lower-limb Resistance to Passive Movement Scale of 0 to 20 [23].

Two experienced therapists blinded to group assignment assessed patients at study entry $\left(\mathrm{T}_{0}\right)$, after 2 weeks $\left(\mathrm{T}_{2}\right)$, after 4 weeks $\left(\mathrm{T}_{4}\right)$, and at follow-up ( $\mathrm{T}_{\mathrm{F}}, 3$ months after study end). Because both therapists were team members, knowledge of the group allocation could not be excluded. The FAC was therefore video-recorded and rated by an experienced therapist on maternity leave, because she was blinded to group assignment.

\section{Statistics}

In case of a missing value, we performed an intentionto-treat analysis; i.e., the assessment was carried on and, if not possible, the last available data was continued. We tested homogeneity between the two groups at study onset with a Mann-Whitney test $(p<0.05)$.

In the first step, we calculated absolute changes over time during the intervention ( $T_{0}$ to $\left.T_{4}\right)$ and during followup ( $\mathrm{T}_{0}$ to $\mathrm{T}_{\mathrm{F}}$ ) and the corresponding 95 percent confidence interval. In the second step, we assessed between-group differences using a nonparametric Mann-Whitney test for two independent samples ( $p<0.025$, Bonferroni adjustment).

\section{RESULTS}

All but one control group patient completed the study (patient did not complete follow-up) (Figure 1). Table 1 summarizes the demographic and clinical data of the two patient groups at study onset, which did not differ. All but one experimental group patient completed the study (patient stopped G-EO System training after 2 weeks because of knee arthritis).

The patients rated the G-EO System positively, including the stair-climbing option; initial fears of overexertion expressed by five patients receded after the first sessions. The G-EO System's recorded treatment parameters 


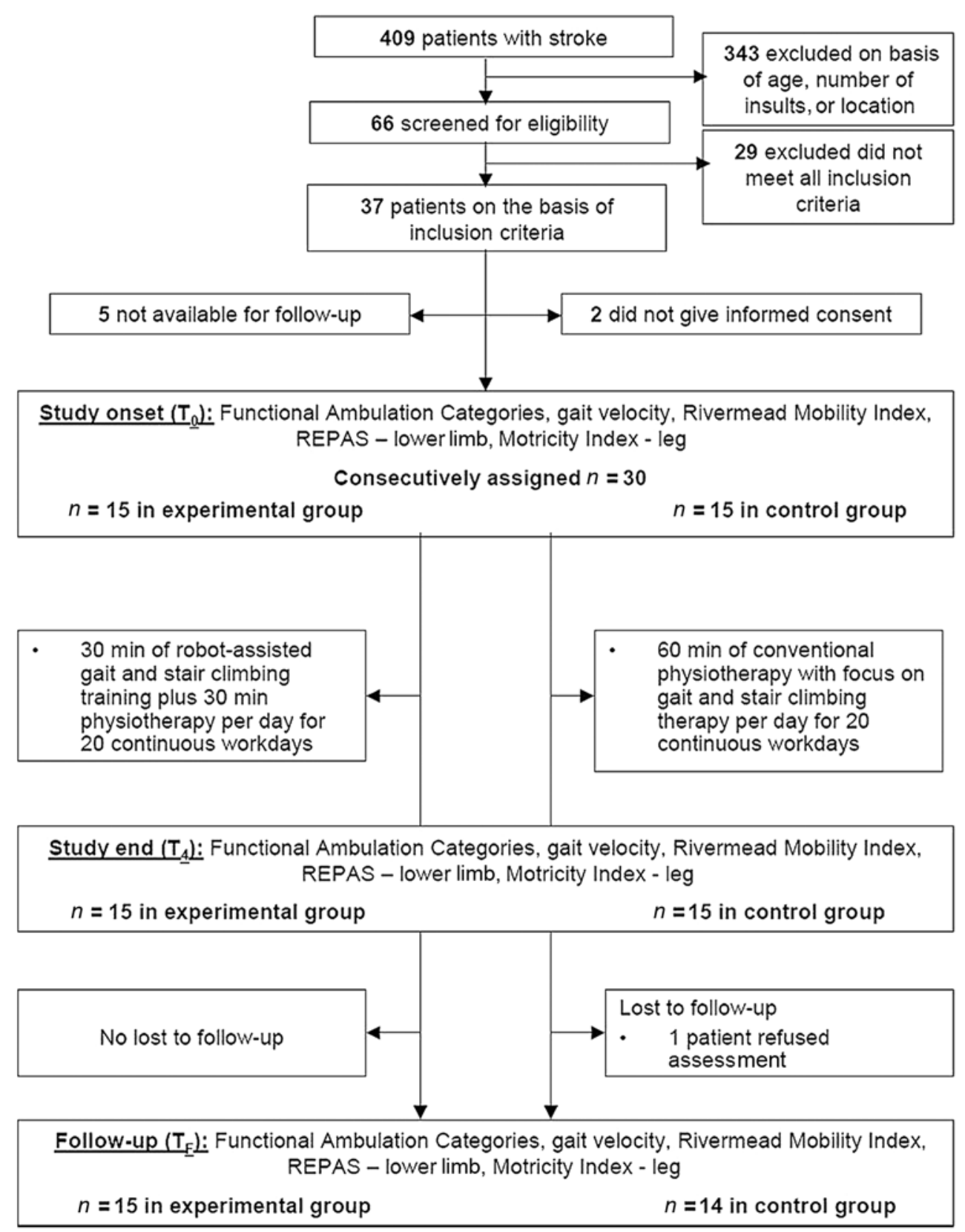

Figure 1.

Flowchart of consecutively assigned patients. REPAS $=$ Resistance to Passive Movement Scale.

indicated that the amount of BWS was continuously reduced and that the net treatment time, training velocity, and training intensity continuously increased.

With respect to the training intensity in both groups, Table 2 summarizes the mean meters covered and the mean stairs climbed per session during the first and second blocks of 10 sessions. The experimental group patients practiced more intensively; in particular, the numbers of stairs climbed differed in favor of the experimental group. Among the 15 control group patients, 11 practiced stair climbing at least once during the first 2 weeks and 13 practiced during the last 2 weeks. Stair climbing was actually part of 3.3 sessions during the first 10 sessions and 4.6 sessions during the last 10 sessions. 
Table 1.

Clinical data of both groups and their initial assessment data.

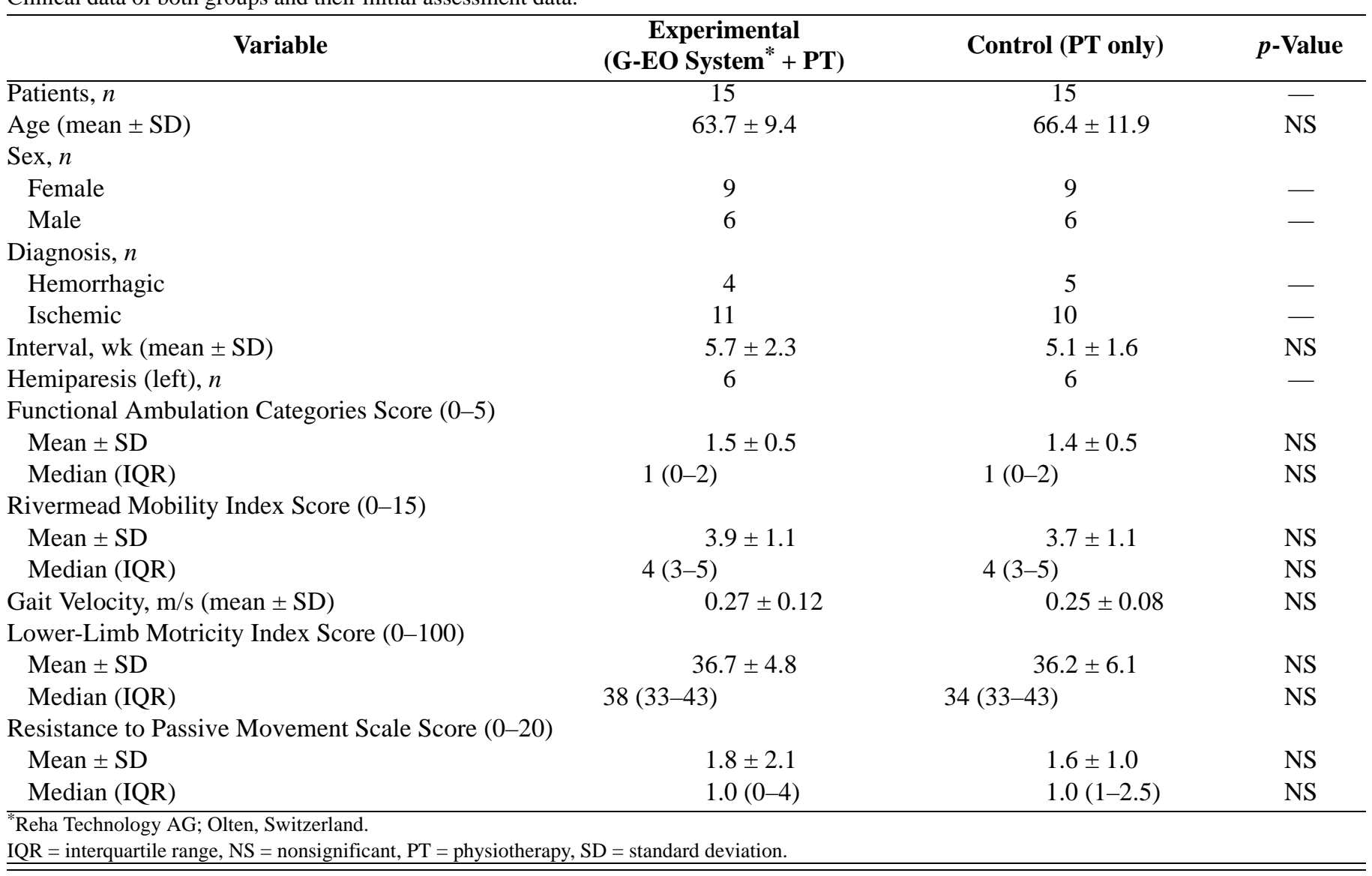

Table 2.

Mean distances covered and number of stairs climbed during therapy sessions of both groups (mean \pm standard deviation).

\begin{tabular}{|c|c|c|c|c|}
\hline \multirow[b]{2}{*}{ Activity } & \multicolumn{3}{|c|}{ Experimental } & \multirow{2}{*}{$\begin{array}{c}\text { Control } \\
\text { PT (60 min) }\end{array}$} \\
\hline & PT (30 min) & $\begin{array}{c}\text { G-EO System* } \\
\text { (30 min) }\end{array}$ & $\Sigma$ & \\
\hline Weeks 1 and 2 & $30.3 \pm 39.4$ & $159.4 \pm 73.9$ & $189.7 \pm 101.1$ & $32.5 \pm 41.6$ \\
\hline Weeks 3 and 4 & $86.4 \pm 52.9$ & $193.7 \pm 84.2$ & $280.1 \pm 108.3$ & $54.5 \pm 55.8$ \\
\hline \multicolumn{5}{|l|}{ Stairs Climbed $(n)$} \\
\hline Weeks 3 and 4 & $25.7 \pm 34.8$ & $161.1 \pm 93.4$ & $186.8 \pm 123.0$ & $10.9 \pm 19.0$ \\
\hline
\end{tabular}

Over time, patients of both groups improved significantly with respect to FAC (Figure 2), gait velocity (Figure 3), RMI, and MI ( $p<0.05)$; muscle tone did not change (Table 3). During the intervention, the experimental group patients improved to a larger extent regarding FAC, gait velocity, RMI, and MI ( $p$ 0.025). During follow-up, the superior effect in favor of the experimental group persisted for the FAC and the MI, whereas gait velocity and the RMI did not differ. Muscle tone did not differ between the two groups at any time (Table 4).

At the end of the study, seven experimental group patients and one control group patient regained the ability 


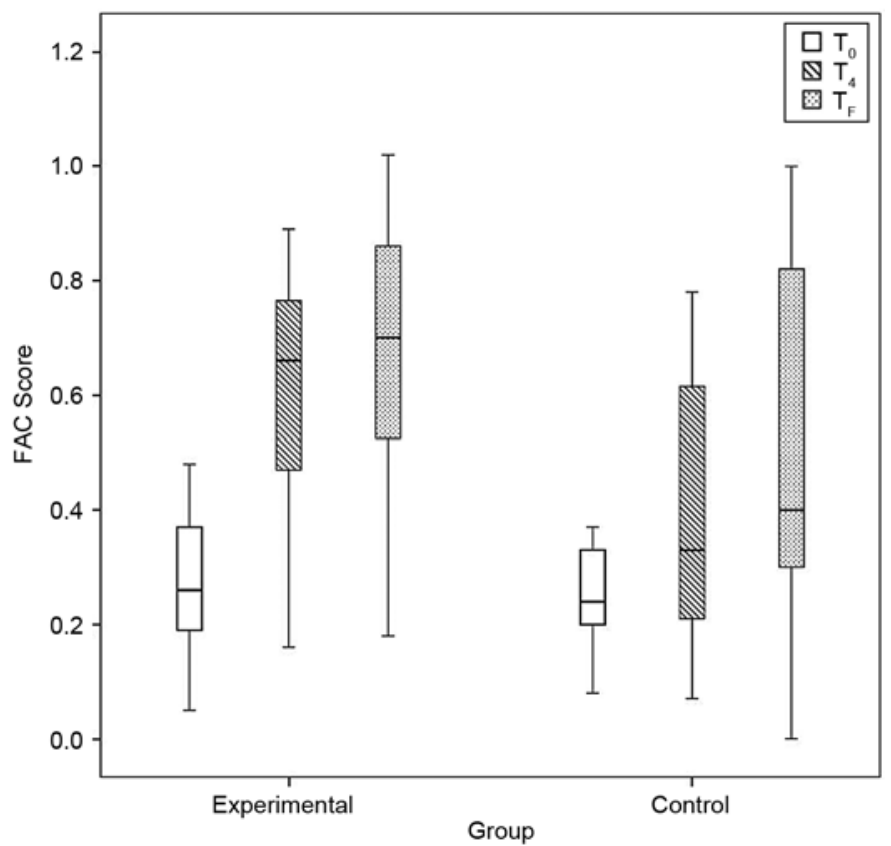

Figure 2.

Box plot of Functional Ambulation Categories (FAC, range: 0-5) of experimental group patients (G-EO System [Reha Technology AG; Olten, Switzerland] + physiotherapy [PT]) and control group patients (PT only) at study onset $\left(\mathrm{T}_{0}\right)$, end of 4-week intervention $\left(T_{4}\right)$, and follow-up $\left(T_{F}\right)$.

to climb up and down at least one flight of stairs independently (FAC score of 5). At follow-up, 11 experimental group patients and 6 control group patients had achieved an FAC score of 5.

\section{DISCUSSION}

The clinical potential of the G-EO System that enabled the repetitive practice of floor walking and stair climbing became apparent. The experimental group patients improved their gait and stair climbing ability to a significantly larger extent and the superior effect persisted at follow-up. Any definite conclusions on the machine's effectiveness in patients with subacute stroke are not yet warranted. The major limitation was the missing randomization of the patients because the two groups were treated consecutively.

Pretests showed that very severely affected patients with stroke, completely unable to walk on the floor or requiring the physical help of two persons (corresponding

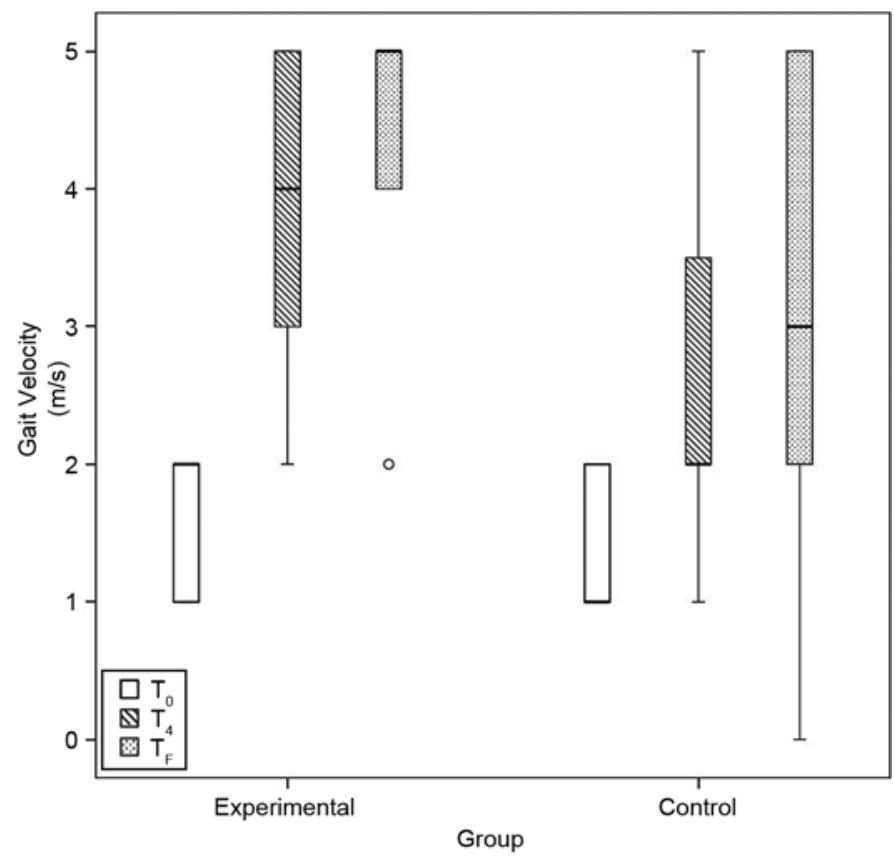

Figure 3.

Box plot of gait velocity $(\mathrm{m} / \mathrm{s})$ of experimental group patients (GEO System [Reha Technology AG; Olten, Switzerland] + physiotherapy $[\mathrm{PT}]$ ) and control group patients (PT only) at study onset $\left(T_{0}\right)$, end of 4-week intervention $\left(T_{4}\right)$, and follow-up $\left(T_{F}\right)$.

to a FAC of score 0), were less suitable candidates. Poor balance and knee control limited their ability to climb stairs up or down; furthermore, they tended to feel unsecure when their feet were lifted too far from the ground. We set the inclusion criteria to an FAC score of $\geq 1$ accordingly. Other potential treatment-related risks were joint arthritis, cardiovascular overexertion, and pressure sores in the groin. One experimental group subject interrupted training because of knee arthritis after 2 weeks.

Gait and stair-climbing ability improved to a significantly larger extent in the experimental group compared with the control group. At the end of the 4-week intervention, seven experimental group patients but only one control group patient had reached an FAC score of 5, indicating both an independent gait and the ability to climb up and down at least one flight of stairs. At follow-up, the superior gait and stair climbing ability in the experimental group persisted.

Both groups, the absolute treatment times, and the remaining rehabilitation program were comparable at study onset. Accordingly, the higher gait and stair climbing intensity probably explained the final superior result 
Table 3.

Mean \pm standard deviation (SD) and 95 percent confidence interval (CI) of each group between end of 4-week intervention and study onset ( $\mathrm{T}_{4}-$ $\mathrm{T}_{0}$ ) and 3-month follow-up and study onset $\left(\mathrm{T}_{\mathrm{F}}-\mathrm{T}_{0}\right)$.

\begin{tabular}{|c|c|c|c|c|c|}
\hline \multirow{2}{*}{ Dependent Variable } & \multirow{2}{*}{ Group } & \multirow{2}{*}{ Mean \pm SD } & \multicolumn{2}{|c|}{$95 \% \mathrm{CI}$} & \multirow{2}{*}{$p$-Value } \\
\hline & & & Lower & Upper & \\
\hline \multirow[t]{2}{*}{ FAC Difference $\mathrm{T}_{4}-\mathrm{T}_{0}$ (score) } & Experimental & $2.4 \pm 1.2$ & 1.799 & 3.021 & $<0.001$ \\
\hline & Control & $1.2 \pm 1.5$ & 0.565 & 1.835 & $<0.001$ \\
\hline \multirow[t]{2}{*}{ FAC Difference $T_{F}-T_{0}$ (score) } & Experimental & $3.0 \pm 0.8$ & 2.581 & 3.419 & $<0.001$ \\
\hline & Control & $1.7 \pm 1.8$ & 0.670 & 2.633 & $<0.001$ \\
\hline Gait Velocity Difference $T_{4}-T_{0}(\mathrm{~m} / \mathrm{s})$ & Experimental & $0.31 \pm 0.17$ & 0.217 & 0.405 & $<0.001$ \\
\hline & Control & $0.25 \pm 0.32$ & 0.074 & 0.432 & $<0.001$ \\
\hline \multirow[t]{2}{*}{ RMI Difference $\mathrm{T}_{4}-\mathrm{T}_{0}$ (score) } & Experimental & $3.8 \pm 2.2$ & 2.576 & 5.024 & $<0.001$ \\
\hline & Control & $2.1 \pm 1.8$ & 1.097 & 3.036 & $<0.001$ \\
\hline \multirow[t]{2}{*}{ RMI Difference $T_{F}-T_{0}$ (score) } & Experimental & $5.8 \pm 3.2$ & 4.046 & 7.554 & $<0.001$ \\
\hline & Control & $3.7 \pm 3.4$ & 1.775 & 5.558 & $<0.001$ \\
\hline & Control & $0.20 \pm 1.7$ & -0.741 & 1.141 & 0.66 \\
\hline \multirow[t]{2}{*}{ MI Difference $\mathrm{T}_{4}-\mathrm{T}_{0}$ (score) } & Experimental & $19.8 \pm 8.4$ & 15.161 & 24.439 & $<0.001$ \\
\hline & Control & $7.6 \pm 10.5$ & 1.789 & 13.411 & $<0.014$ \\
\hline \multirow[t]{2}{*}{ MI Difference $\mathrm{T}_{\mathrm{F}}-\mathrm{T}_{0}$ (score) } & Experimental & $31.4 \pm 13.8$ & 23.744 & 39.056 & $<0.001$ \\
\hline & Control & $18.8 \pm 11.8$ & 12.260 & 25.340 & $<0.001$ \\
\hline
\end{tabular}

in the experimental group. The mean distance covered per $60 \mathrm{~min}$ session was six times higher in the experimental group. For stair climbing, the experimental group patients even climbed 20 times more steps per session. This difference is explained by the G-EO System's characteristics enabling the repetitive practice of stair climbing, but also by the fact that the experimental group patients and their therapists practiced stair climbing within their 30 min PT session as intensively as the control group patients within their 60 min PT session. The combined therapy of the experimental group resulted in a faster recuperation of gait, thus reducing the effort for the patients and their therapists on real stairs.

Numerous stroke studies have shown the obvious correlation between intensity of gait practice and the mobility outcome, be it in terms of additional locomotor training [24], treadmill training with BWS [25-26], or gait machines [9]. In addition, intense locomotor training resulted in improved cardiovascular fitness in patients with subacute [27] and chronic [28] stroke, activation of subcortical neural networks [29], and skeletal muscle changes with improved insulin action [30-31].
One may argue that the practice of stair climbing is premature in nonambulatory patients with stroke. First, it is commonly applied within the Bobath technique to promote a most physiological stance and swing phase [32]. Second, the knowledge transfer from one motor task to another seems limited [33]. Third, short bouts of stair climbing provided a strong cardiovascular training effect in sedentary young women [34].

The major limitations of the study are obvious: the two groups were not randomized, but rather assigned consecutively, and the patient number $(n=30)$ was small. In addition, a very experienced therapist provided the robot therapy, and blind assessment could not be fully guaranteed because the raters were team members. The FAC was video-recorded and rated by an external colleague.

\section{CONCLUSIONS}

The novel gait G-EO System robot offers nonambulatory patients with stroke the ability to repetitively practice both simulated floor walking and stair climbing. 
Table 4.

Mean \pm standard deviation (SD) of each group between end of 4-week intervention and study onset $\left(\mathrm{T}_{4}-\mathrm{T}_{0}\right)$ and 3-month follow-up and study onset $\left(\mathrm{T}_{\mathrm{F}}-\mathrm{T}_{0}\right)$ and $p$-value of difference between groups at study onset and 3-month follow-up.

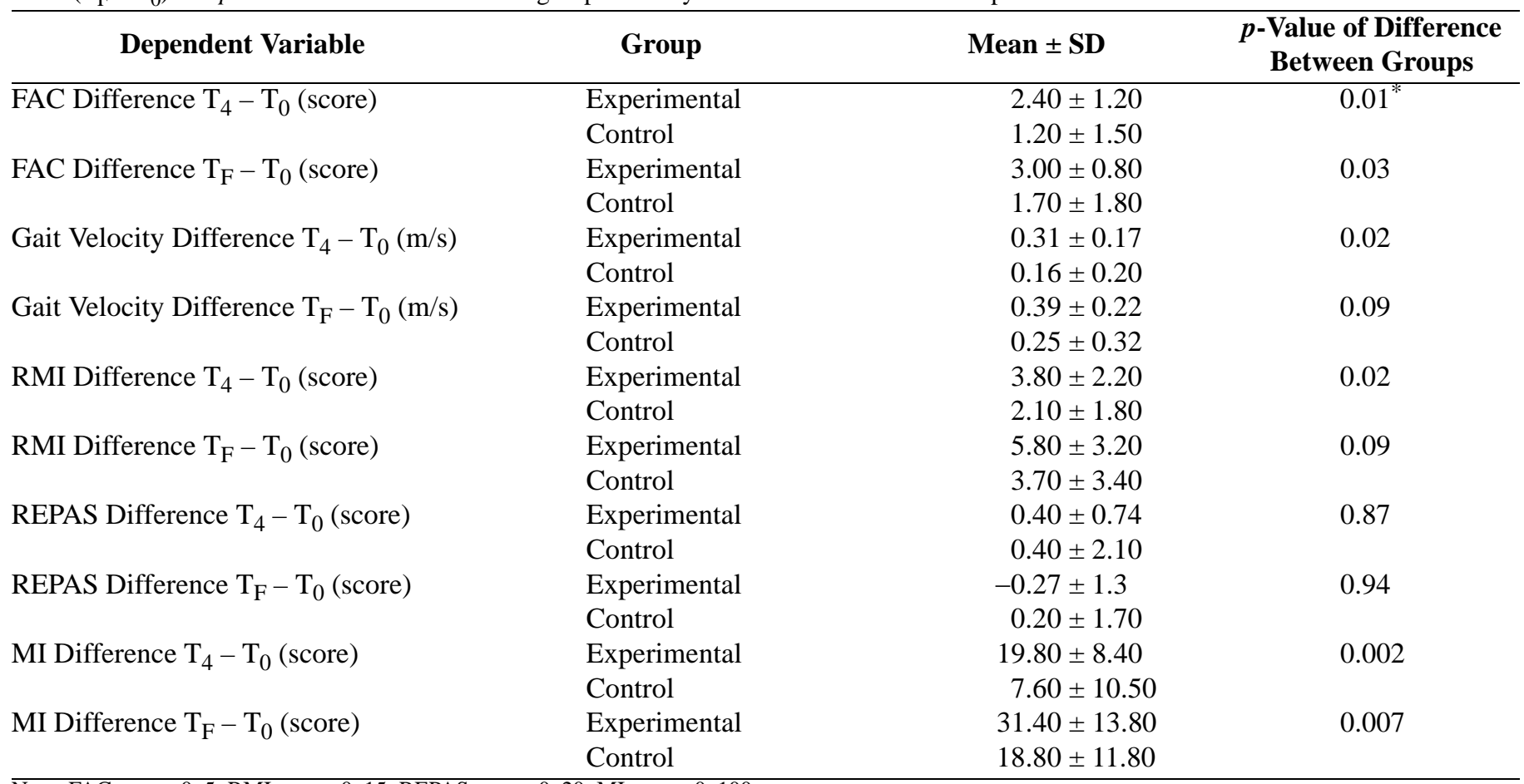

Note: FAC range: 0-5; RMI range: 0-15; REPAS range: 0-20; MI range: 0-100.

${ }^{*}$ Significant difference between groups, $p \leq 0.025$.

FAC = Functional Ambulation Categories, MI = Motricity Index, REPAS = Resistance to Passive Movement Scale, RMI = Rivermead Mobility Index.

Because of the higher training intensity, the experimental group patients reached a superior gait and stair climbing ability after the intervention and at follow-up. At present, no definite conclusions on the G-EO System's effectiveness are warranted and a robust randomized controlled trial should follow.

\section{ACKNOWLEDGMENTS}

\author{
Author Contributions: \\ Study design: A. Waldner. \\ Principal investigator: S. Hesse. \\ Patient treatment: C. Tomelleri, A. Bardeleben. \\ Assessment: C. Werner. \\ Data management: C. Werner. \\ Drafting of manuscript: S. Hesse, C. Werner. \\ Technical support: C. Tomelleri.
}

Financial Contributions: Reha Technology AG holds the international patent for the G-EO System. Drs. Hesse and Waldner are shareholders of the company, but the company had no involvement in the study design; the collection, analysis, and interpretation of the data; the writing of the article; or the decision to submit the article for publication.
Funding/Support: This material was unfunded at the time of manuscript preparation.

Institutional Review: Participants provided written consent in the study approved by the local ethical committee.

Participant Follow-Up: The authors do not plan to inform the participants of the publication of this study.

\section{REFERENCES}

1. Kolominsky-Rabas PL, Heuschmann PU, Marschall D, Emmert M, Baltzer N, Neundörfer B, Schöffski O, Krobot KJ. Lifetime cost of ischemic stroke in Germany: Results and national projections from a population-based stroke registry: The Erlangen Stroke Project. Stroke. 2006;37(5): 1179-83. [PMID:16574918]

http://dx.doi.org/10.1161/01.STR.0000217450.21310.90

2. Dobkin BH. Strategies for stroke rehabilitation. Lancet Neurol. 2004;3(9):528-36. [PMID:15324721] http://dx.doi.org/10.1016/S1474-4422(04)00851-8

3. Hesse S, Bertelt C, Schaffrin A, Malezic M, Mauritz KH. Restoration of gait in nonambulatory hemiparetic patients by treadmill training with partial body-weight support. Arch 
Phys Med Rehabil. 1994;75(10):1087-93. [PMID:7944913] http://dx.doi.org/10.1016/0003-9993(94)90083-3

4. Franceschini M, Carda S, Agosti M, Antenucci R, Malgrati D, Cisari C; Gruppo Italiano Studio Allevio Carico Ictus. Walking after stroke: What does treadmill training with body weight support add to overground gait training in patients early after stroke?: A single-blind, randomized, controlled trial. Stroke. 2009;40(9):3079-85. [PMID:19556526]

http://dx.doi.org/10.1161/STROKEAHA.109.555540

5. Peurala SH, Tarkka IM, Pitkänen K, Sivenius J. The effectiveness of body weight-supported gait training and floor walking in patients with chronic stroke. Arch Phys Med Rehabil. 2005;86(8):1557-64. [PMID:16084808] http://dx.doi.org/10.1016/j.apmr.2005.02.005

6. Tong RK, Ng MF, Li LS. Effectiveness of gait training using an electromechanical gait trainer, with and without functional electric stimulation, in subacute stroke: A randomized controlled trial. Arch Phys Med Rehabil. 2006; 87(10):1298-1304. [PMID:17023237] http://dx.doi.org/10.1016/j.apmr.2006.06.016

7. Pohl M, Werner C, Holzgraefe M, Kroczek G, Mehrholz J, Wingendorf I, Hoölig G, Koch R, Hesse S. Repetitive locomotor training and physiotherapy improve walking and basic activities of daily living after stroke: A single-blind, randomised multi-centre trial (DEutsche GAngtrainerStudie, DEGAS). Clin Rehabil. 2007;21(1):17-27.

[PMID: 17213237]

http://dx.doi.org/10.1177/0269215506071281

8. Schwartz I, Sajin A, Fisher I, Neeb M, Shochina M, KatzLeurer M, Meiner Z. The effectiveness of locomotor therapy using robotic-assisted gait training in subacute stroke patients: A randomized controlled trial. PM R. 2009;1(6): 516-23. [PMID:19627940] http://dx.doi.org/10.1016/j.pmrj.2009.03.009

9. Mehrholz J, Werner C, Kugler J, Pohl M. Electromechanicalassisted training for walking after stroke. Cochrane Database Syst Rev. 2007;4(4):CD006185. [PMID:17943893]

10. Colombo G, Joerg M, Schreier R, Dietz V. Treadmill training of paraplegic patients using a robotic orthosis. J Rehabil Res Dev. 2000;37(6):693-700. [PMID:11321005]

11. Veneman JF, Kruidhof R, Hekman EE, Ekkelenkamp R, Van Asseldonk EH, Van der Kooij H. Design and evaluation of the LOPES exoskeleton robot for interactive gait rehabilitation. IEEE Trans Neural Syst Rehabil Eng. 2007; 15(3):379-86. [PMID:17894270] http://dx.doi.org/10.1109/TNSRE.2007.903919

12. Hesse $S$, Uhlenbrock D. A mechanized gait trainer for restoration of gait. J Rehabil Res Dev. 2000;37(6):701-8. [PMID:11321006]

13. Freivogel S, Schmalohr D, Mehrholz J. Improved walking ability and reduced therapeutic stress with an electromechanical gait device. J Rehabil Med. 2009;41:734-39.

[PMID:19774307]

http://dx.doi.org/10.2340/16501977-0422
14. Hesse S, Welz A, Assmann E, Quentin B, Waldner A. [Pedestrians in Berlin after stroke. Recommendations for street and subway transit]. Nervenarzt. 2009;80(8):953-58. German. [PMID:19343316] http://dx.doi.org/10.1007/s00115-009-2700-x

15. Paolucci S, Bragoni M, Coiro P, De Angelis D, Fusco FR, Morelli D, Venturiero V, Pratesi L. Quantification of the probability of reaching mobility independence at discharge from a rehabilitation hospital in nonwalking early ischemic stroke patients: A multivariate study. Cerebrovasc Dis. 2008; 26(1):16-22. [PMID:18511867] http://dx.doi.org/10.1159/000135648

16. Hesse S, Waldner A, Tomelleri C. Innovative gait robot for the repetitive practice of floor walking and stair climbing up and down in stroke patients. J Neuroeng Rehabil. 2010; 7:30-40. [PMID:20584307]

http://dx.doi.org/10.1186/1743-0003-7-30

17. Schmidt H, Werner C, Bernhardt R, Hesse S, Krüger J. Gait rehabilitation machines based on programmable footplates. J Neuroeng Rehabil. 2007;4:2-4. [PMID:17291335] http://dx.doi.org/10.1186/1743-0003-4-2

18. Hussein S, Schmidt H, Volkmar M, Werner C, Helmich I, Piorko F, Krüger J, Hesse S. Muscle coordination in healthy subjects during floor walking and stair climbing in robot assisted gait training. Conf Proc IEEE Eng Med Biol Soc. 2008;2008:1961-64. [PMID:19163075]

19. Mahoney FI, Barthel DW. Functional evaluation: The Barthel Index. Md State Med J. 1965;14:61-65. [PMID:14258950]

20. Holden MK, Gill KM, Magliozzi MR. Gait assessment for neurologically impaired patients. Standards for outcome assessment. Phys Ther. 1986;66(10):1530-39.

[PMID:3763704]

21. Collen FM, Wade DT, Bradshaw CM. Mobility after stroke: Reliability of measures of impairment and disability. Int Disabil Stud. 1990;12(1):6-9. [PMID:2211468] http://dx.doi.org/10.3109/03790799009166594

22. Demeurisse G, Demol O, Robaye E. Motor evaluation in vascular hemiplegia. Eur Neurol. 1980;19(6):382-89. [PMID:7439211] http://dx.doi.org/10.1159/000115178

23. Platz T, Vuadens P, Eickhof C, Arnold P, Van Kaick S, Heise K. REPAS, a summary rating scale for resistance to passive movement: Item selection, reliability and validity. Disabil Rehabil. 2008;30(1):44-53. [PMID:17852258] http://dx.doi.org/10.1080/09638280701191743

24. Kwakkel G, Wagenaar RC, Twisk JW, Lankhorst GJ, Koetsier JC. Intensity of leg and arm training after primary middlecerebral-artery stroke: A randomised trial. Lancet. 1999; 354(9174):191-96. [PMID:10421300] http://dx.doi.org/10.1016/S0140-6736(98)09477-X

25. Hesse S, Bertelt C, Jahnke MT, Schaffrin A, Baake P, Malezic M, Mauritz KH. Treadmill training with partial body weight support compared with physiotherapy in nonambulatory 
hemiparetic patients. Stroke. 1995;26(6):976-81. [PMID:7762049] http://dx.doi.org/10.1161/01.STR.26.6.976

26. Ada L, Dean CM, Hall JM, Bampton J, Crompton S. A treadmill and overground walking program improves walking in persons residing in the community after stroke: A placebocontrolled, randomized trial. Arch Phys Med Rehabil. 2003; 84(10):1486-91. [PMID:14586916] http://dx.doi.org/10.1016/S0003-9993(03)00349-6

27. Eich HJ, Mach H, Werner C, Hesse S. Aerobic treadmill plus Bobath walking training improves walking in subacute stroke: A randomized controlled trial. Clin Rehabil. 2004; 18(6):640-51. [PMID:15473116] http://dx.doi.org/10.1191/0269215504cr779oa

28. Macko RF, Ivey FM, Forrester LW, Hanley D, Sorkin JD, Katzel LI, Silver KH, Goldberg AP. Treadmill exercise rehabilitation improves ambulatory function and cardiovascular fitness in patients with chronic stroke: A randomized, controlled trial. Stroke. 2005;36(10):2206-11. [PMID:16151035] http://dx.doi.org/10.1161/01.STR.0000181076.91805.89

29. Luft AR, Macko RF, Forrester LW, Villagra F, Ivey F, Sorkin JD, Whitall J, McCombe-Waller S, Katzel L, Goldberg AP, Hanley DF. Treadmill exercise activates subcortical neural networks and improves walking after stroke: A randomized controlled trial. Stroke. 2008;39(12):3341-50. [PMID:18757284] http://dx.doi.org/10.1161/STROKEAHA.108.527531

30. Hafer-Macko CE, Ryan AS, Ivey FM, Macko RF. Skeletal muscle changes after hemiparetic stroke and potential beneficial effects of exercise intervention strategies. J Rehabil Res Dev. 2008;45(2):261-72. [PMID:18566944] http://dx.doi.org/10.1682/JRRD.2007.02.0040

31. Ryan AS, Macko RF, Peters MN, Ivey FM, Prior SJ, Joseph LJ, Hafer-Macko CE. Plasma adiponectin levels are associ- ated with insulin sensitivity in stroke survivors. J Stroke Cerebrovasc Dis. 2009;18(3):214-20. [PMID:19426893]

http://dx.doi.org/10.1016/j.jstrokecerebrovasdis.2008.10.001

32. Davies PM. Right in the middle, selective trunk activity in the treatment of adult hemiplegia. Berlin (Germany): Springer-Verlag; 1990.

33. Winstein CJ, Gardner ER, McNeal DR, Barto PS, Nicholson DE. Standing balance training: Effect on balance and locomotion in hemiparetic adults. Arch Phys Med Rehabil. 1989;70(10):755-62. [PMID:2802955]

34. Boreham CA, Kennedy RA, Murphy MH, Tully M, Wallace WF, Young I. Training effects of short bouts of stair climbing on cardiorespiratory fitness, blood lipids, and homocysteine in sedentary young women. Br J Sports Med. 2005;39(9):590-93. [PMID:16118293] http://dx.doi.org/10.1136/bjsm.2002.001131

Submitted for publication August 15, 2011. Accepted in revised form October 26, 2011.

This article and any supplementary material should be cited as follows:

Hesse S, Tomelleri C, Bardeleben A, Werner C, Waldner A. Robot-assisted practice of gait and stair climbing in nonambulatory stroke patients. J Rehabil Res Dev. 2012; 49(4):613-22.

http://dx.doi.org/10.1682/JRRD.2011.08.0142

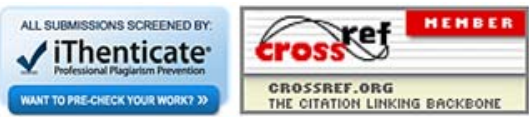

